\title{
Explicaciones básicas al proyecto de comunas y división territorial del municipio de Cali
}

\section{JAIME GALARZA SAMCLEMENTE*}

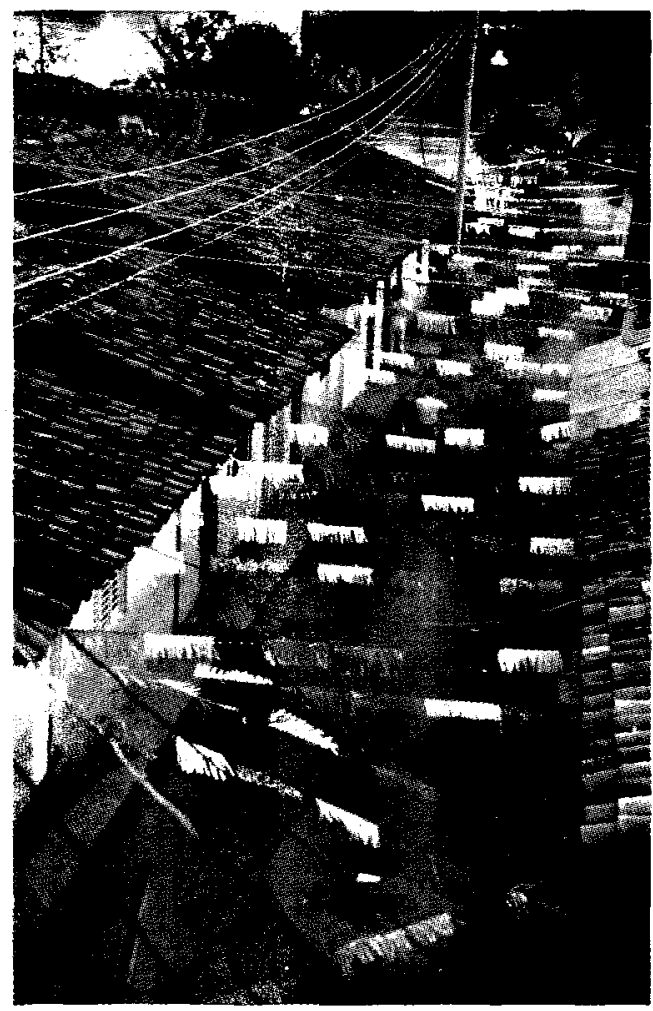

Decoraciones típicas de Barrios Populares.

* Profesor titular, Facultad de Ciencias de la Administración Universidad del Valle.
1. Naturaleza legal de las comunas y corregimientos

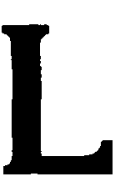

as comunas y corregimientos son divisiones geográficas de los municipios para una mejor administración de los servicios que éste presta (Art. $311 \mathrm{CRM}$ ). Esto quiere decir que el legislador no creó una nueva entidad con personería jurídica, es decir un nuevo ente DESCENTRALIZADO TERRITORIALMENTE.

En ese sentido no existió por parte del Legislador la intención de crear, por así decirlo, municipios más pequeños, cuando precisamente la tendencia legislativa, en materia de reordenamiento territorial, es integrar departamentos en regiones de planificación y municipios en asociaciones y áreas metropolitanas para no mencionar sino aquellos que tienen fuerza legal, pues de tiempo atrás se discute la conveniencia de integrar municipios en comarcas o provincias. 
Por esa razón, la propuesta sobre comunas y corregimientos inicia su articulado aclarando este punto, importante para definir la naturaleza de las juntas administradoras locales.

\section{Naturaleza legal de las juntas administradoras locales}

Para el Proyecto de acuerdo en cuestión, las Juntas Administradoras locales son cuerpos colegiados, que tienen jurisdicción sobre las comunas ocorregimientos, con competencias y funciones administrativas básicamente de carácter reglamentario, asesor, de control y vigilancia y no hacen parte de la estructura de gobierno del municipio.

Las razones en las cuales se fundamenta esta interpretación, son las siguientes:

Los municipios son entes descentralizados territorialmente, es decir que gozan de personería jurídica, autonomía administrativa y patrimonial. Por ese motivo la constitución y la Ley le han otorgado competencia administrativa, la cual desarrolla de manera autónoma, pero con la tutela del departamento.

Por el contrario, al no ser las comunas y corregimientos entes descentralizados territorialmente, la constitución y la ley no les han otorgado competencia administrativa. Como veremos más adelante la competencia administrativa le fue delegada a las juntas administradoras locales convirtiéndolas en un ente desconcentrado, y no es un nuevo poder de gobierno del municipio.

La competencia administrativa de los municipios está constituida por el conjunto de funciones y servicios que les asigna la Ley (Art. 11 CRM). Esas funciones administrativas son de orden reglamentario y ejecutivo. Las de tipo ejecutivo se relacionan con la planeación, organización, dirección, control y operación de los servicios e inversión de obras en los municipios. La estructura de gobierno del municipio ha sido concebida para la distribución de sus competencias y funciones administrativas y la componen las siguientes autoridades:

a) Una corporación administrativa de elección popular, denominada Concejo Municipal, que reglamenta por medio de acuerdo lo conveniente para administración del municipio. En ese sentido sus funciones son básicamente de:

- Control Político Administrativo.

- Reglamentaria (Expedición de normas administrativas de carácter general).

- Deliberativas sobre propuestas de otras autoridades municipales.

b) Una autoridad administrativa de carácter ejecutivo cuya figura es el alcalde con sus respectivas dependencias centralizadas y descentralizadas por servicios (establecimientos públicos, empresas industriales, etc.). La ley señala que la atención de las funciones, la prestación de los servicios y la ejecución de las obras a cargo de los municipios se hará directamente por éstos a través de sus 


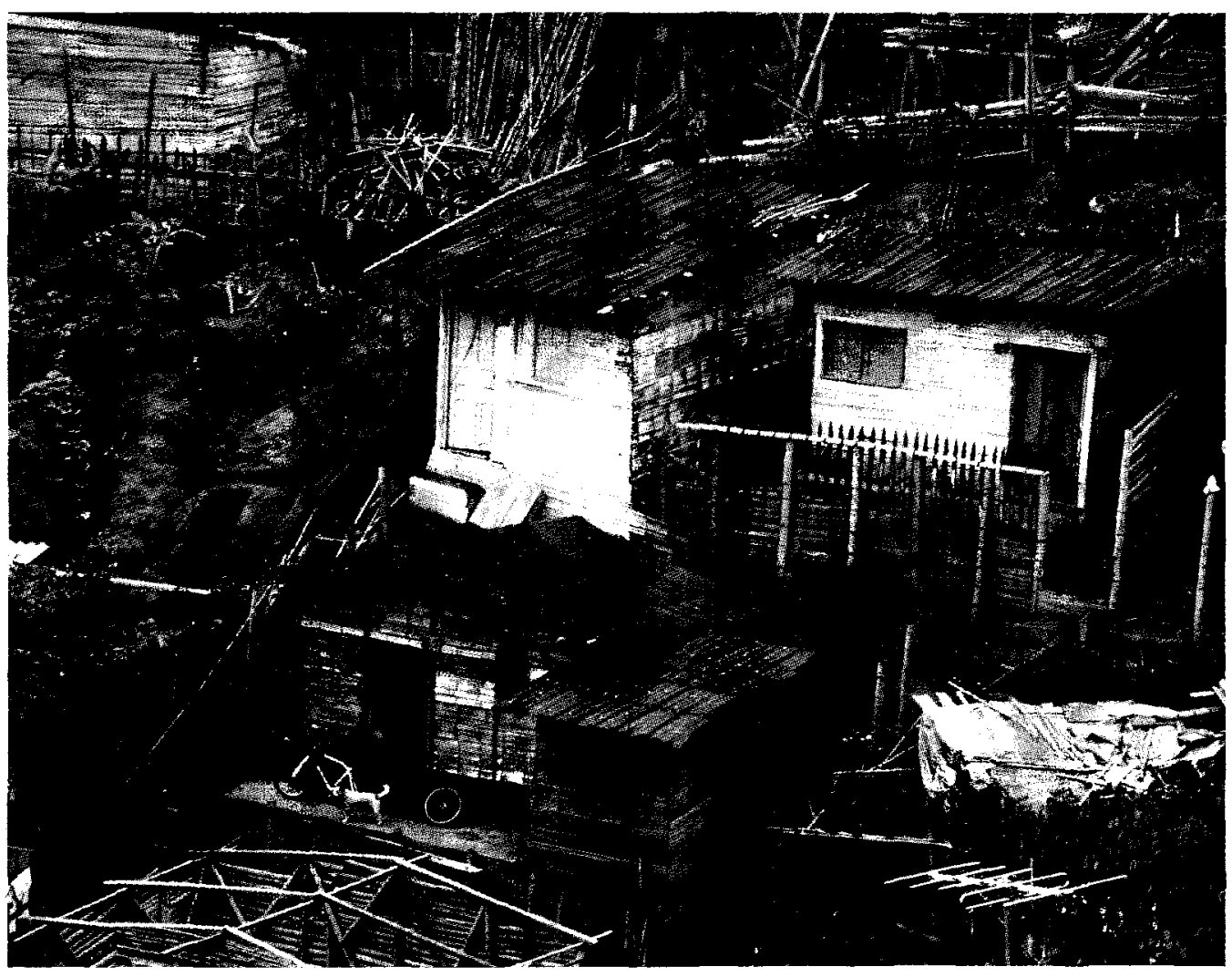

Cali, Barnos de invasión en sus primeras etapas. 
dependencias centrales o de sus entidades descentralizadas o por otras personas en razón de los contratos y asociaciones que para el efecto se celebren o constituyan (Art. 12 CRM).

Igualmente el alcalde es el jefe de la administración pública en el municipio y ejecutor de los acuerdos del Concejo y ostenta la representación legal de éste.

c) Un organismo de vigilancia, la Personería Municipal.

d) La Tesorería Municipal, cuyo titular será de libre nombramiento y remoción del alcalde a partir de junio de 1988.

e) Una Contraloría Municipal para municipios con un presupuesto de 50 millones.

El nuevo régimen municipal trae, en el título sobre divisiones administrativas de los municipios, la figura de comunas y corregimientos y de juntas administradoras locales.

La Ley otorgó a las juntas administradoras locales, mediante los Arts. 312 y 315 del CRM, las siguientes competencias administrativas del siguiente tenor:

Otorgadas directamente por la Ley:

- Proponer motivamente la inclusión en el presupuesto municipal de partidas para sufragar gastos de programas adoptados para el área de su jurisdicción (participación en la planeación).

- Recomendar la aprobación de determinados impuestos y contribuciones (función asesora).
- Vigilar y controlar la prestación de los servicios municipales, la expedición de determinadas medidas y velar por el cumplimiento de sus decisiones (función asesora y de control).

- Las juntas administradoras locales distribuirán y așignarán las partidas que a su favor se incluyan en los presupuestos nacionales, departamentales, municipales y de sus entidades descentralizadas. (Función de coordinación).

Así mismo, apropiarán el valor de los impuestos, sobre tasas y contribuciones que se establezcan por el Concejo exclusivamente para la respectiva comuna o corregimiento y los demás ingresos que reciban por cualquier otro concepto. (Función de coordinación).

Otorgadas por el Concejo Municipal

Cumplir con delegación del Concejo Municipal, mediante resoluciones, lo conveniente para la administración del área de su jurisdicción y las demás funciones que la Ley les señale a éstos. Las funciones que el Concejo Municipal puede delegar como puede leerse son muy amplias y variadas concretamente son funciones reglamentarias referidas a todas y cada una de las dimensiones de funcionamiento e inversión de los municipios. Con seguridad son medidas que tienen que ver con Planeación - presupuestación, coordinación, control de los servicios que prestan sus dependencias centrales y descentralizadas de la alcaldía y tal vez con la operación de esos servicios. Pero 
lo importante a destacar es que serán generales, que requieren ser ejecutadas, cumplidas por el alcalde y sus inmediatos colaboradores.

Los cuerpos colegiados con competencias administrativas no tienen esas prerrogativas de gestión operativa y por tanto, en el caso que nos ocupa, el Concejo no puede delegar a las juntas administradoras locales lo que no tiene.

De lo precedente se desprenden varias conclusiones, a saber:

- Que las distintas autoridades del mucipio cumplen funciones administrativas.

- Que de acuerdo con la misión básica de la autoridad sus funciones serán preponderantemente reglamentarias o deliberativas, o de control o de dirección o de operación, etc.

- Que de manera expresa la ley les otorga a las dependencias centrales y descentralizadas bajo control del alcalde dentro de un conjunto de funciones administrativas, exclusivamente las referidas a la operación de los servicios y ejecución de obra. Ningún otro organismo o autoridad del municipio tiene esta prerrogativa.

- Que la ley le otorga a las juntas administradoras locales, por delegación del Concejo, funciones y competencias básicamente reglamentarias, en los diferentes campos del funcionamiento de servicios e inversiones del municipio, y directamente funciones asesoras de control y coordinación.

\section{De las funciones de}

\section{las juntas administradoras locales}

Consecuente con lo anterior el proyecto de acuerdo sobre comunas, corregimientos y juntas administradoras locales, no otorga a las juntas administradoras locales competencias y funciones ejecutivas o de decisión sobre la operación de servicios y ejecución de obras, por cuanto:

- La Ley, como lo hemos señalado, no se las otorga a las juntas administradoras locales.

- La ley señala directamente al alcalde y sus dependencias centrales y descentralizadas estas funciones.

- La ley otorga la posibilidad a las organizaciones comunitarias de realizar funciones de operación de servicios mediante convenios con las dependencias centrales $y$ descentralizadas de la alcaldía.

- La Ley faculta a la misma ley y a los Concejos para que en las comunas y corregimientos puedan actuar autoridades o funcionarios de carácter ejecutivo (Art. 316, inciso 2 ㅇ CRM).

No obstante lo anterior y en aras de hacer más efectivo el papel de las Juntas Administradoras Locales, la Reforma Adninistrativa presentada contempla los siguientes mecanismos a saber:

- La creación de una nueva dependencia central denominada Vicealcaldía Territorial con el propósito de asignarle la vigilancia y el control de 
las operaciones de servicios en las áreas de jurisdicción de las comunas y corregimientos y la ejecución de obras menores.

- La creación de los directores de comunas y corregimientos, bajo la subordinación de la vicealcaldía territorial, con competencia básica de inventariar permanentemente los problemas y necesidades sentidos de los habitantes de las comunas y corregimientos para ser tenidos en cuenta por la planeación del municipio y la programación operativa de las dependencias encargadas de la prestación de servicios y ejecución de obras.

- Congruente con lo anterior, se le asignan a las juntas administradoras locales funciones de asesoría, vigilancia respecto a la programación de las necesidades y problemas sentidos de la comunidad y la ejecución de los mismos por parte de lạs dependencias municipales. Asílas juntas administradoras locales cobran la dimensión participativa y verdaderamente administrativa que piden algunos.

- Por otro lado el proyecto de acuerdo consigna la gran mayoría (se dejaron por fuera dos funciones asesoras), de las funciones que la Ley les otorga directamente a las juntas administradoras locales y desarrolla la función relativa al control y vigilancia en la prestación de los servicios municipales.

De esa manera y como conclusión general de lo anterior, en las comunas y corregimientos no sólo actuarán juntas administradoras locales con competencias administrativas derivadas del Concejo Municipal, sino que también la Administración Municipal ejecutiva desciende a las comunas para participar en consonancia con las juntas, en operación de servicios y ejecución de obras menores.

Las Juntas Administradoras Locales abandonadas a sus competencias de Ley nada podrían hacer en el campo efectivo de los servicios si la autoridad ejecutiva del municipio no asume, facultada por la Ley (Art. 316, Inciso 20, CRM), responsabilidades para la satisfacción de los problemas y necesidades de los habitantes de las comunas.

\section{Delimitación de}

\section{comunas $\mathrm{y}$}

\section{corregimientos}

El proyecto de acuerdo trae la propuesta de 7 comunas para el casco urbano del municipio y 15 corregimientos para su área rural.

Igualmente para efectos de planificación, recolección de información y periodización de necesidades comunitarias, se podrá subdividir las comunas en sectores que tiendan a una homogeneidad socio-económica. La propuesta de comunas de 200 mil habitantes para una ciudad como Cali, va en relación proporcional a la población urbana cercana al 1.500.000 habitantes y es consistente con la naturaleza de las 
juntas administradoras y las comunas. En efecto si las juntas administradoras locales van a tener funciones administrativas de carácter reglamentario, asesor y distribución de partidas presupuestales, impuestos e ingresos, y la administración municipal ejecutiva presta sus servicios a través de programas operativos (con base a planes generales de desarrollo), que implican cierta globalidad e integración, la consecuencia son territorios geográficamente significativos poblacionalmente importantes. De otro lado, si las juntas administra- barrio. doras locales son cuerpos colegiados de siete miembros, con funciones administrativas de carácter básicamente reglaméntario y asesor, sus actos son necesariamente generales, impersonales dirigidos al mayor número de personas. Si estos organismos tuvieran que actuar desarrollando funciones operativas de prestación directa de servicio se justificarían divisiones geográficas más acordes con tal realidad, tal como ocurre con las juntas de acción comunal, que tienen funciones de operación de servicios y por esa razón su ámbito es el

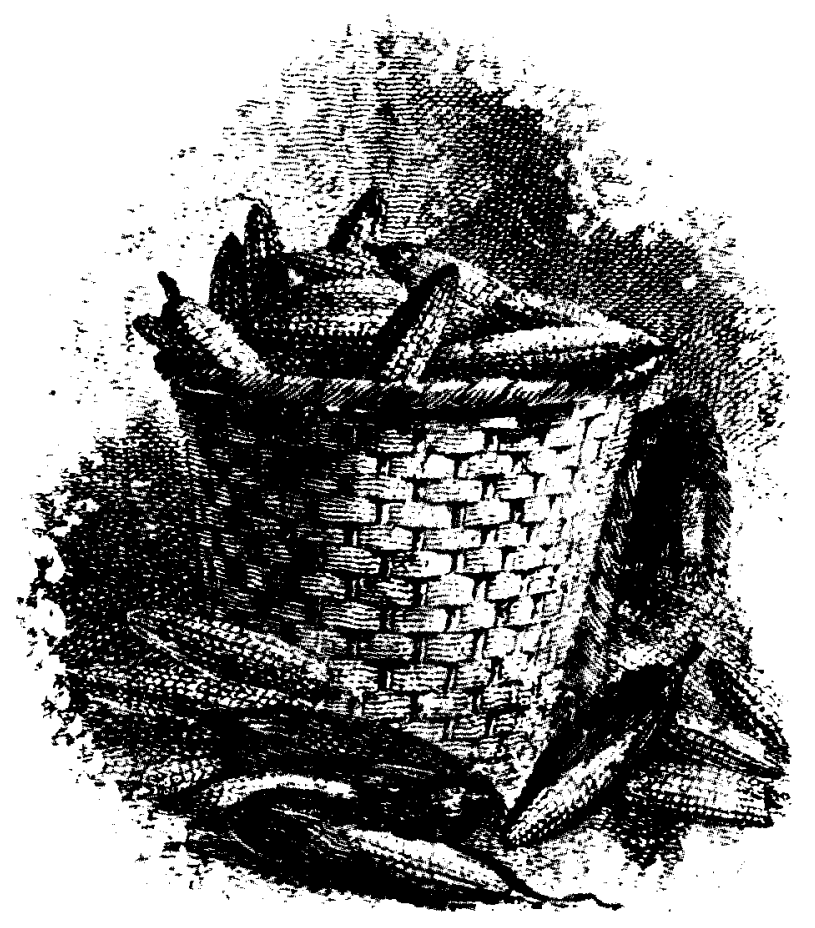

